\title{
The Role of Sex Research Organizations in Eliminating Sexual Harassment
}

\author{
E. Sandra Byers ${ }^{1} \cdot$ Brian Mustanski $^{2} \cdot$ Scott Semenyna $^{3} \cdot$ Kelly D. Suschinsky $^{4,6}$ (D) Eric Vilain ${ }^{5}$
}

Received: 31 May 2019 / Revised: 19 June 2019 / Accepted: 20 June 2019 / Published online: 1 July 2019

(c) Springer Science+Business Media, LLC, part of Springer Nature 2019

Herbenick et al. (2019) have provided a thoughtful discussion of sexual harassment in the field of sexuality research that we believe will help inspire future dialogue and action. We are in full agreement that sexual harassment has and does occur in our field and that it is totally unacceptable and should not be tolerated. Indeed, the Executive Committee of the International Academy of Sex Research (IASR) had been discussing these issues prior to the publication of Herbenick et al.'s Guest Editorial with an eye toward ensuring that our meetings are respectful and safe for all participants. At the same time, we recognize differing opinions and debate are part of the scientific process, and wish to foster an environment that allows an open exchange of ideas and opinions. We thank Herbenick et al. for contributing to the conversation and raising a range of important issues that we will need to consider. As such, we are working toward developing a Code of Conduct related to sexual and gender harassment that will spell out expectations that such harassment is not tolerated at IASR, reduce the likelihood of such behavior occurring within IASR and its meetings, and spell out reporting policies as well as consequences that will result from these types of behaviors. We expect to provide the membership with the opportunity to engage in discussion about sexual harassment in our organization as well as to

Kelly D. Suschinsky

iasradmin@gmail.com

1 Department of Psychology, University of New Brunswick, Fredericton, NB, Canada

2 Institute for Sexual and Gender Minority Health and Wellbeing, Northwestern University, Chicago, IL, USA

3 Department of Psychology, University of Lethbridge, Lethbridge, AB, Canada

4 Department of Psychology, Queen's University, Kingston, ON, Canada

5 Center for Genetic Medicine Research, Children's National Health System, Washington, DC, USA

6 International Academy of Sex Research http://www.iasrsite.org/ provide input into the proposed Code of Conduct at the annual Business Meeting in Mexico City in July 2019.

IASR is a scientific society whose objectives are the promotion of high standards of research and scholarship in the field of sexual behavior by fostering communication among scholars engaged in such research at its annual meeting. We recognize that we can only achieve this laudable goal by fostering an environment where the sharing of science and intellectual debate can be anchored in respect, diversity, inclusion, and equity. With the support of our leadership, it is the responsibility of all IASR members to address and prevent all forms of discrimination and harassment at our meeting-including sexual harassment. We look forward to engaging with the membership on this important work.

Acknowledgements The authors comprise the 2018/2019 Executive of the International Academy of Sex Research (Byers, Mustanski, Suschinsky, and Vilain), as well as our student representative (Semenyna).

\section{Compliance with Ethical Standards}

Conflict of interest The authors declare that they have no conflicts of interest.

Informed Consent We did not collect data from participants and thus did not require informed consent.

\section{Reference}

Herbenick, D., van Anders, S. M., Brotto, L. A., Chivers, M. L., JawedWessel, S., \& Galarza, J. (2019). Sexual harassment in the field of sexuality research [Guest Editorial]. Archives of Sexual Behavior, 48, 997-1006. https://doi.org/10.1007/s10508-019-1405-x.

Publisher's Note Springer Nature remains neutral with regard to jurisdictional claims in published maps and institutional affiliations. 